\title{
First-line immunotherapy in non-small cell lung cancer patients with poor performance status: a systematic review and meta-analysis
}

\author{
Francesco Facchinetti ${ }^{1}$, Massimo Di Maio ${ }^{2}$, Fabiana Perrone ${ }^{3}$, Marcello Tiseo ${ }^{3,4}$ \\ ${ }^{1}$ Université Paris-Saclay, Institut Gustave Roussy, Inserm, Biomarqueurs Prédictifs et Nouvelles, Stratégies Thérapeutiques en Oncologie, Villejuif, \\ France; ${ }^{2}$ Department of Oncology, University of Turin, Ordine Mauriziano Hospital, Torino, Italy; ${ }^{3}$ Medical Oncology Unit, University Hospital of \\ Parma, Parma, Italy; ${ }^{4}$ Department of Medicine and Surgery, University of Parma, Parma, Italy \\ Contributions: (I) Conception and design: All Authors; (II) Administrative support: None; (III) Provision of study materials or patients: None; (IV) \\ Collection and assembly of data: All Authors; (V) Data analysis and interpretation: All Authors; (VI) Manuscript writing: All authors; (VII) Final \\ approval of manuscript: All authors. \\ Correspondence to: Francesco Facchinetti, MD MSc. Université Paris-Saclay, Institut Gustave Roussy, Inserm, Biomarqueurs Prédictifs et Nouvelles, \\ Stratégies Thérapeutiques en Oncologie, 114 Rue Édouard Vaillant, 94800 Villejuif, France. Email: Francesco.Facchinetti@gustaveroussy.fr.
}

Background: Immune checkpoint inhibitors (ICIs) have become the standard of care for the first-line treatment of advanced non-small cell lung cancer patients (NSCLC), either as single agents or combined with chemotherapy. The evidence sustaining their role for poor performance status (ECOG PS $\geq 2$ ) patients is limited.

Methods: We search PubMed and the proceedings of international oncology meetings to perform a systematic review to assess the outcomes poor PS NSCLC patients who received ICIs as first-line treatment. A meta-analysis included retrospective studies focusing on pembrolizumab monotherapy in PD-L1 $\geq 50 \%$ NSCLC. We reported the global objective response rate (ORR), disease control rate (DCR) and landmark progression-free and overall survival (PFS and OS, respectively) in ECOG PS $\geq 2$ and $0-1$ patients, respectively.

Results: Forty-one studies were included in the systematic review. Thirty-two retrospective studies focused on pembrolizumab monotherapy in PD-L1 $\geq 50 \%$ cases. In total, 1,030 out of 5,357 (19\%) of patients across 30 studies presented with a PS $\geq 2$ at pembrolizumab initiation. In 18 studies with detailed clinical information, worse outcomes in poor PS compared to good PS patients were documented. The meta-analysis revealed that ORR and DCR within the PS $\geq 2$ patient population were $30.9 \%$ and $41.5 \%$ respectively (55.2\% and $71.5 \%$ in PS $0-1$ patients). The rates of PFS (at 3, 6, 12 and 18 months) and OS (at 6, 12, 18 and 24 months) were approximately double in the good PS compared to the poor PS group of patients. In the three prospective trials where of ICIs in PS 2 populations, the diverse strictness in PS definition likely contributed to the differential outcomes observed. Six retrospective studies dealt with chemo-immunotherapy combinations.

Conclusions: Still with limited prospective evidence sustaining the role of immunotherapy in previously untreated NSCLC with poor PS, 19\% of patients in retrospective series dealing with pembrolizumab in PDL1 $\geq 50 \%$ tumors had an ECOG PS $\geq 2$. Clinical effort encompassing the definition of poor PS, of the factors conditioning it, and the development of dedicated treatment strategies is required to improve the outcomes in this patient population.

Keywords: Non-small cell lung cancer (NSCLC); pembrolizumab; PD-1; PD-L1; immune checkpoint inhibitors (ICIs); ECOG PS 2

Submitted Jan 07, 2021. Accepted for publication Mar 17, 2021.

doi: $10.21037 /$ tlcr-21-15

View this article at: http://dx.doi.org/10.21037/tlcr-21-15 


\section{Introduction}

Treatment algorithms in non-small cell lung cancer (NSCLC) have been revolutionized since the introduction of immune checkpoint inhibitors (ICIs). After the initial demonstration of benefit in the setting of patients suffering from metastatic disease who had already failed systemic chemotherapy, agents directed against the PD-1/PD$\mathrm{L} 1$ axis are now the standard of care as the upfront, first-line treatment of advanced NSCLC. In addition, immunotherapy drugs have improved the outcomes in locally-advanced disease and their role in localized stages is going to be defined.

The first contribution of ICIs in the first-line treatment of NSCLC was provided by pembrolizumab (anti-PD-1) mono-therapy, as it was showed to be superior compared to chemotherapy in patients whose tumors express PD-L1 in at least $50 \%$ of malignant cells according to immunohistochemistry evaluation (PD-L1 $\geq 50 \%$ ) (1). Combination of pembrolizumab with chemotherapy is the standard treatment across all PD-L1 scores $(2,3)$, and the question whereas patients with $\mathrm{PD}-\mathrm{L} 1 \geq 50 \%$ should be treated with the PD-1 inhibitor alone or in association with cytotoxic agents is of major clinical relevance, in the absence of a direct comparison among the two strategies. Atezolizumab (anti-PD-L1) combined with carboplatin, paclitaxel, bevacizumab is approved for the treatment of EGFR-mutated NSCLC patients after progression to targeted inhibitors (4), while the association of ipilimumab (anti-CTLA-4) and nivolumab (anti-PD-1) with two courses of chemotherapy received recently FDA and EMA approval in first-line independently from PD-L1 expression and histology (5). Several other regimens have been proven superior to standard chemotherapy, and the roaster of immunotherapy options for the first-line treatment of advanced NSCLC patients is going to expand (6).

These therapeutic attitudes, emerging from the outstanding results in clinical trials, are translated in the clinical practice, where "real-life" patients are less selected, especially in terms of disease aggressiveness and comorbidities, globally affecting their performance status (PS) (7).

All clinical studies, initially envisaging a role for ICIs in NSCLC and then leading to their approval, have enrolled good PS patients (PS 0-1 according to ECOG, Eastern Cooperative Oncology Group) (8). Good PS patients either maintain their status and activities as before disease diagnosis (ECOG PS 0), either are limited only in strenuous activity and work, without affecting of normal daily activities
(ECOG PS 1). Poor PS patients are not able to carry any work activity, still ambulatory, fully capable of selfcare and up more than $50 \%$ of waking hours (ECOG PS 2), or only partially autonomous in selfcare and confined to bed or chair more than $50 \%$ of waking hours (ECOG PS 3), while ECOG PS 4 patients are completely disabled. PS, representing an estimation of patients' global fitness, figure among the most solid prognostic factors in lung cancer (9-12), as well as across other disease types and stages. As an alternative to ECOG measure, Karnofsky score (ranging from 100 -best-to 0 -worst-) is used to assess patients' fitness as well $(8,13)$.

Patients presenting with a poor PS represent a relevant proportion of subjects at lung cancer diagnosis (30\% approximately), with pulmonary malignancies representing the most frequently associated with an ECOG PS $\geq 2(14,15)$. Several factors can impact (or concur) on PS deterioration, mainly represented by the burden of the disease itself, the presence of comorbidities and the global fragility of elderly people.

In the absence of molecular alterations allowing targeted treatment with rapid and clinically relevant responses achievable in a short delay without relevant toxicities (16), only PS 2 patients are actively evaluated for the administration of systemic therapy, while ECOG PS 3 are usually candidate to best supportive care (BSC) only. Despite its epidemiological relevance, the population of patients with ECOG PS 2 is scarcely represented in clinical studies encompassing chemotherapy regimens $(7,15)$. Considering the lack of robust evidence, current guidelines suggest personalized therapeutic approaches (with regard to chemotherapy, single drugs or carboplatin-based doublets) $(17,18)$.

Albeit real-life experiences have showed similar results to clinical trials in pretreated populations of NSCLC patients receiving ICIs, poor PS status remain a strong negative prognostic factor for immunotherapy, as reported by prospective clinical studies (Table 1) and retrospective evidence (reviewed by Dall'Olio et al.) (26). As ICIs administration has been moved to the first-line setting, proofs are needed to assess their contribution in poor PS status and to define the outcomes achievable in this population in order to inform clinical practice and to design ad boc clinical trials. In this sense, we performed a systematic review and metaanalysis gathering clinical evidence on ICI for the first-line treatment of NSCLC patients with a poor PS.

We present the following article in accordance with the PRISMA reporting checklist (available at http://dx.doi. org/10.21037/tlcr-21-15). 


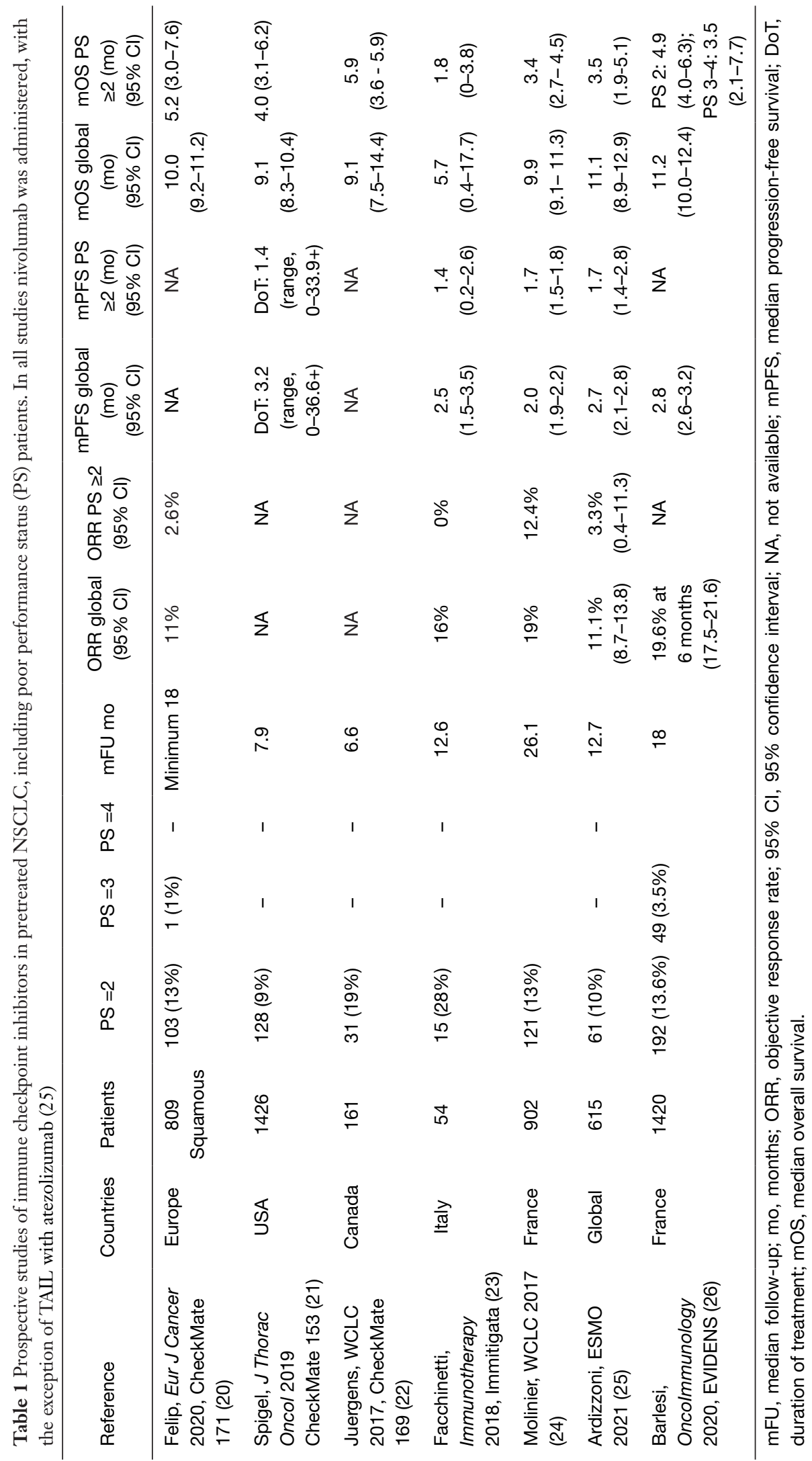




\section{Methods}

\section{Search strategy and selection criteria}

The review was performed according to Preferred Reporting Items for Systematic Reviews and Meta-Analyses (PRISMA) guidelines (27). The search was conducted in accordance with the principles outlined in the Cochrane Handbook for Systematic Reviews of Interventions. The database searched was MEDLINE (data cutoff of December $\left.1^{\text {st }}, 2020\right)$. The search items were "(NSCLC OR lung cancer) AND (checkpoint inhibitor OR PD-1 OR PD-L1 OR nivolumab OR pembrolizumab OR atezolizumab OR durvalumab OR avelumab) AND first line"; "poor PS AND (NSCLC OR lung cancer) AND (checkpoint inhibitor OR PD-1 OR PD-L1 OR nivolumab OR pembrolizumab OR atezolizumab OR durvalumab OR avelumab)"; "PS 2 AND (NSCLC OR lung cancer) AND (checkpoint inhibitor OR PD-1 OR PD-L1 OR nivolumab OR pembrolizumab OR atezolizumab OR durvalumab OR avelumab)".

The first objective of our analysis was indeed to report, among the global population receiving first-line immunotherapy, the quote of patients with a PS $\geq 2$. The key inclusion criteria for this analysis was the description of the precise number of patients with either a good and a poor PS and a PD-L1 $\geq 50 \%$, treated with a PD-1/PD-L1 inhibitor single-agent in the first-line setting. Studies including only one of the two PS groups, not allowing the calculation of the proportion, were excluded from this synthesis. The second main objective of our analysis was to perform a meta-analysis of studies including patients receiving firstline pembrolizumab, gathering events of ORR, DCR and landmark survival estimations differentially in ECOG PS $0-1$ and $\geq 2$ cases. To be included in the meta-analysis, studies should report at least one measure of activity [i.e., objective response and disease control rates (ORR and DCR respectively), progression-free survival (PFS)] and/or efficacy [overall survival (OS)] in the poor PS population. Given that the large majority of studies reporting the outcomes of $\mathrm{PS} \geq 2$ patients were retrospective, only these were included in the analysis.

We encountered studies reporting only statistical analyses on the differential outcomes between PS 0-1 and $\geq 2$ cases, without a definite assessment of poor PS patients in terms of ORR, DCR, PFS or OS. These studies, considered for the description of proportion of poor PS but not for the meta-analysis, were included in Tables reporting the respective outcomes.

Exclusion criteria were: articles not written in English, reviews, commentaries, opinions, case reports, not relevant articles. Case reports tend to describe the positive outcomes of patients? in specific situations of interest, suggesting an intrinsic publication bias (i.e., the histories of poor PS NSCLC receiving ICIs are normally published only if successful). Accordingly, case series were considered only if consecutive patients were included, excluding the possibility of selection bias.

\section{Data extraction and risk of bias assessment}

Two reviewers (FF and FP) independently screened titles and abstracts of all identified references. Full-text of the documents of potential interest were independently assessed by the two reviewers, to determine whether they satisfied the inclusion criteria, without meeting the exclusion ones. Any disagreements were solved by consensus or arbitration by a third person (MT). A data extraction form was developed specifically for the purpose of this assessment to collect information on patient characteristics, type of treatments, and outcome measures.

\section{Data synthesis and analysis}

Descriptive statistics were used to summarize characteristics data of patients and tumors. The main results were summed in a table and a quantitative synthesis was planned for all the reported cases.

Meta-analysis on ORR, DCR and on PSF/OS rates, was performed with MedCalc Statistical Software version 19.4.1 (MedCalc Software Ltd., Ostend, Belgium; https:// www.medcalc.org; 2020). The software uses a FreemanTukey transformation (arcsine square root transformation) to calculate the weighted summary proportion under the fixed and random effects model. Heterogeneity is measured by Cochran's Q, calculated as the weighted sum of squared differences between individual study proportion and the pooled proportion across studies. Q is distributed as a chisquare statistic with $\mathrm{k}$ (number of studies) minus 1 degrees of freedom. When the number of included studies is small, Q has low power to test heterogeneity, whilst Q has too much power if the number of studies is large. The $\mathrm{I}^{2}$ statistic describes the percentage of variation across studies that is due to heterogeneity rather than chance. $I^{2}=100 \% \times$ (Q-df)/Q. Unlike Q it does not inherently depend upon the number of studies considered.

The likelihood of publication bias was assessed by both Egger's and Begg's tests. 
For the calculation of the pooled probability of being event-free at prespecified time points $(3,6,12$ and 18 months for PFS; 6, 12, 18 and 24 months for OS), only trials displaying numbers of patients at risk at each defined landmark time were included in the pooled population; when not available, the probability of being event-free for each specific time points was inferred, with approximation, from Kaplan-Meier survival curves. Given the unavailability of standard errors/confidence intervals for the probability, in the pooled calculation the probability reported in each trial was weighted by the number of patients at risk. Details about the proportion of patients event-free at the reported time points and the respective patient at risk, not present in the work of Cortellini et al. (28) and of Facchinetti et al. (29), were kindly provided by the authors.

\section{Results}

\section{Results of the systematic research}

Our research items in MEDLINE led to the identification of 1107 titles, while 16 records were identified in main international meeting proceedings (Figure 1). After removing duplicates and excluding non-pertinent studies, 51 items were assessed for eligibility. Ten of them were excluded: five as not fulfilling inclusion criteria for either quantitative or qualitative analyses, five as reporting data on patients' cohort already present in another studies, where poor PS patients were more represented or follow-up was longer. Among these studies, the group of Cortellini firstly reported the activity and efficacy of first-line pembrolizumab in PD-L1 $\geq 50 \%$ NSCLC patients (28), then dealing with toxicity outcomes in the same population (30). Finally, 41 studies were included in the systematic review.

Thirty-two studies were retrospective and dealt with pembrolizumab given in the first-line setting in selected populations of $\mathrm{PD}-\mathrm{L} 1 \geq 50 \%$ NSCLC (Table 2). The analysis of proportion of poor PS patients, and the meta-analysis of treatment outcomes were focused on these studies. Thirty studies included both good and poor PS patients (allowing the calculation of proportion of poor PS patients, Table S1), while Facchinetti et al. and Inaba-Higashiyama et al. only dealt with ECOG PS 2 and 3-4 patients, respectively (29,53). Meta-analysis of treatment outcomes included 18 studies (Table S2). When the detail is present, PS 2 cases were usually far more represented then and PS 3 ones (Table 2), and this repartition is likely to be similar in studies reporting the number of "PS $\geq 2$ " patients, supposing a very low number of PS 3 patients actively treated.

Three prospective phase 2 trials dedicating to PS 2 patients were identified, two of them enrolled patients regardless of PD-L1 status [PePS2 (61), CheckMate 817 (62)], while SAKK 19/17 had PD-L1 cut-off of $\geq 25 \%$ to allow patients to enter the study and receive upfront durvalumab (63) (Table 3). In PePS2, patient received pembrolizumab monotherapy across treatment lines, while CheckMate 817 enrolled different cohorts of patients to be treated with nivolumab and ipilimumab.

Three retrospective studies reported the experiences of real-life chemo-immunotherapy combinations, while additional three ones dealt with the therapeutic choice of administering either pembrolizumab as monotherapy or combined with cytotoxic agents for the first-line treatment of NSCLC, selected or not for PD-L1 $\geq 50 \%$ (Table 4).

\section{Retrospective studies on first-line pembrolizumab: outcomes of poor PS and comparison with good PS patients}

Pooling the data of the 30 studies including patients regardless of their PS (quantitative analysis of the proportion of poor PS patients), 1,030 out of 5,357 (19\%) of patients presented with a PS $\geq 2$ at pembrolizumab initiation. Within each series, the rate of poor PS patients ranged from $10 \%$ and $37 \%$, with a median of $20 \%$.

\section{Response and DCRs}

ORR and DCR (detailed for PS $\geq 2$ patients in eight and six studies, respectively), in the global populations as well as dichotomized in good and poor PS patient, are reported in Table 5, while Figure 2 depicts the meta-analyses for PS $\geq 2$ patients. No publication biases were found at a significance level $<0.05$. When compared to PS $0-1$ patients, poor PS ones had frequently worse response and DCRs, and in many cases the difference was statistically significant (Table 5). Pooling the data, 491 and 210 PS $\geq 2$ patients were evaluated for ORR [seven studies $(28,29,39,40,44,45,50)$ ] and DCR [five studies $(29,35,36,39,40)$ ], respectively (Figures S1,S2). Disease responses were observed in $30.9 \%$ of the cases [95\% CI: $22.5-40.0 \%]$ and $41.5 \%$ of the patient achieved disease control (95\% CI: 27.1-56.9\%) (Figure 2). Significant and moderate heterogeneity was recognized for ORR $\left(\mathrm{I}^{2}=72.3 \%, 95 \%\right.$ CI: $40.1-87.2 \% ; \mathrm{P}=0.0014)$ and DCR $\left(\mathrm{I}^{2}=60.4 \%, 95 \%\right.$ CI: $0.0-$ $85.2 \% ; \mathrm{P}=0.0389$ ) estimations, respectively (Figures $\mathrm{S} 1, \mathrm{~S} 2$ ).

Across studies, 1,262 ECOG PS 0-1 patients in five studies were evaluated for disease response $(28,39,44,45,50)$ and ORR was 55.2\% (95\% CI: 42.8-67.2\%) (Figure 2C; 

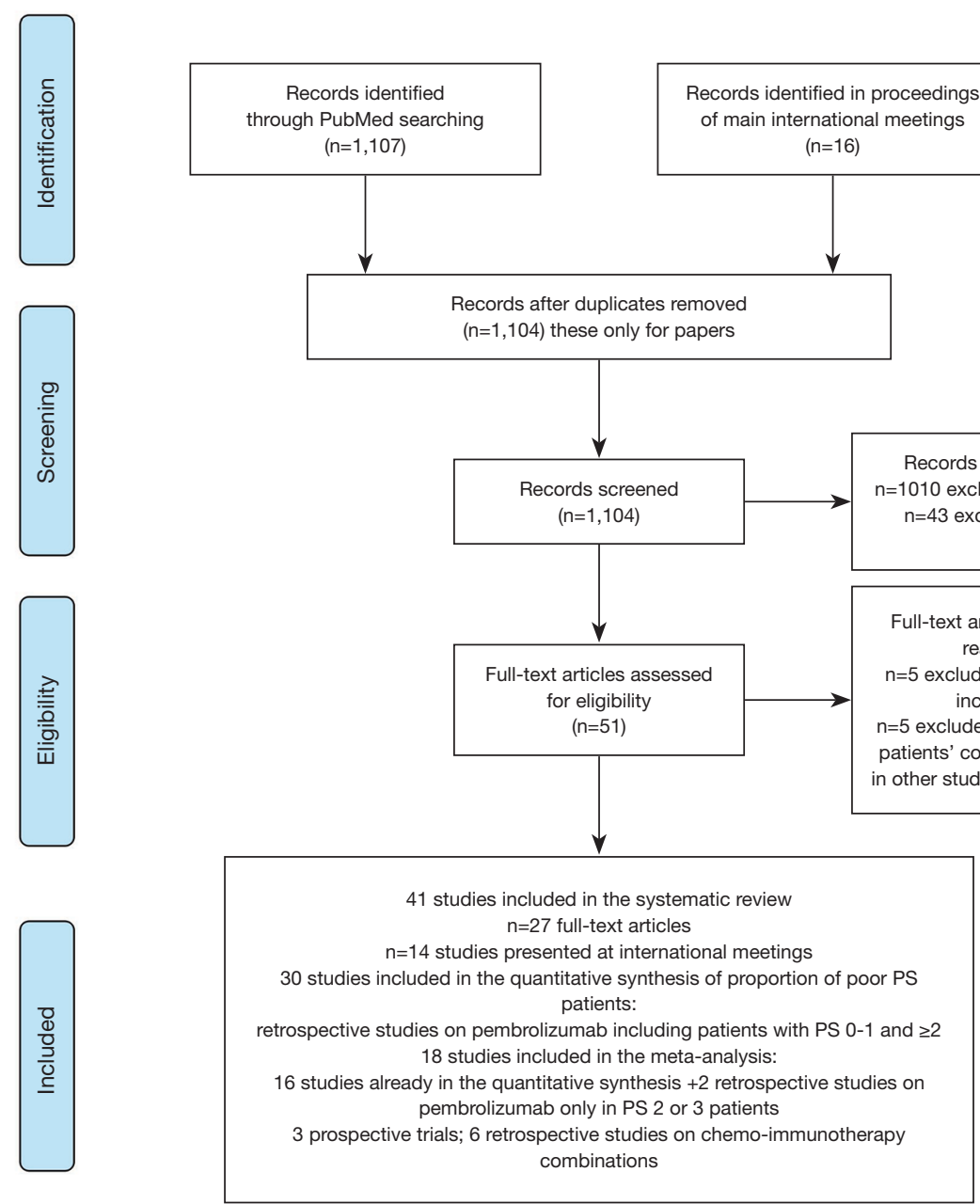

Figure 1 PRISMA flow diagram describing the process leading to the identification of studies included in the systematic review and meta-analysis.

Figure S3). DCR data was obtained for 185 patients in four studies $(35,36,39,50)$ and occurred in $71.5 \%$ of the cases (95\% CI: 56.0-84.7\%) (Figure 2D; Figure S2). Heterogeneity was significant for both ORR $\left(\mathrm{I}^{2}=92.6 \%\right.$, 95\% CI: $85.6-95.1 \% ; \mathrm{P}<0.0001)$ and DCR $\left(\mathrm{I}^{2}=79.45 \%\right.$, 95\% 45.28-92.28\%; P=0.0022) (Figures S3,S4).

\section{Progression-free survival}

Twenty-one studies provided information on PFS of poor PS patients, 18 only reporting their numbers and the comparison with PS $0-1$ cases, while median PFS estimations for the poor PS group were provided in 15 studies (Table 6). Almost invariably, PS $\geq 2$ was associated with shorter PFS compared to good PS. With the limitations intrinsic to the meaning of median survival estimations in immunotherapy studies (70) and to the retrospective nature of the studies themselves, with different time-points evaluations and definitions of disease progression according to local clinical practice, median PFS ranged from less than $1(35,39)$ to approximately 7 months, 
Table 2 Retrospective studies including poor PS patients treated with first-line pembrolizumab in PD-L1 $\geq 50 \%$ NSCLC

\begin{tabular}{|c|c|c|c|}
\hline Study & Country & Patients & Poor PS patients [\%] \\
\hline Tamiya, Invest New Drugs 2019 (33) & Japan & 213 & $32 \mathrm{PS}=2 ; 9 \mathrm{PS}=3 ; 1 \mathrm{PS}=4$ [20] \\
\hline Aguilar, Ann Oncol 2019 (34) & USA & 187 & $34 \mathrm{PS} \geq 2[18]$ \\
\hline Edahiro, Plos One 2019 (35) & Japan & 149 & $24 \mathrm{PS}=2 ; 7 \mathrm{PS}=3 / 4$ [21] \\
\hline Kuzminin, WCLC 2019 (37) & Argentina & 74 & $9 \mathrm{PS}=2[12]$ \\
\hline Rubio, ESMO 2019 (38) & Spain & 223 & $52 \mathrm{PS}=2 ; 3 \mathrm{PS}=3$ [25] \\
\hline Frost, ESMO 2019 (39) & Germany & 129 & $28 \mathrm{PS}=2 ; 3 \mathrm{PS}=3[24]$ \\
\hline Imai, J Cancer Res Clin Oncol 2020 (40) & Japan & $47 \geq 75$ years & $7 \mathrm{PS}=2 ; 3 \mathrm{PS}=3[21]$ \\
\hline Amrane, Cancer Med 2020 (43) & France & 108 & $25 \mathrm{PS}=2[23]$ \\
\hline Facchinetti, Eur J Cancer 2020 (29) & Italy & 153 & $153 \mathrm{PS}=2[100]$ \\
\hline Cortellini, Clin Lung Cancer 2020 (30) & Italy & 1026 & $179 \mathrm{PS} \geq 2[17]$ \\
\hline Cavaille, Tumori 2020 (44) & France & 41 & $6 \mathrm{PS}=2 ; 5 \mathrm{PS}=3$ [27] \\
\hline Alessi, J Immunother Cancer 2020 (45) & USA & 234 & $39 \mathrm{PS}=2[17]$ \\
\hline Friedlaender, Acta Oncol 2020 (46) & Europe & 302 & $56 \mathrm{PS}=2[19]$ \\
\hline Seban, Cancers (Basel) 2020 (47) & France & 63 & $13 P S \geq 2[21]$ \\
\hline Banna, Transl Lung Cancer Res 2020 (48) & Europe & 132 & $22 \mathrm{PS}=2[17]$ \\
\hline Inaba-Higashiyama, Thorac Cancer 2020 (31) & Japan & 4 & $3 \mathrm{PS}=4[100]$ \\
\hline Yamaguchi, Thorac Cancer 2021 (54) & Japan & 72 & $23 \mathrm{PS}=2 / 3$ [32] \\
\hline Wakuda, Lung Cancer 2020 (55) & Japan & 87 & $9 \mathrm{PS}=2[10]$ \\
\hline Sehgal, ASCO 2020 (56) & USA & 54 & $21 \mathrm{PS} \geq 2[39]$ \\
\hline Pilotto, ESMO 2020 (57) & Italy & 27 & $8 \mathrm{PS}=2 ; 1 \mathrm{PS}=3$ [33] \\
\hline Lobefaro, ESMO 2020 (58) & Italy & 146 & $17 \mathrm{PS}=2[12]$ \\
\hline Lester, ESMO 2020 (59) & UK & 179 & $22 \mathrm{PS} \geq 2[12]$ \\
\hline Mouritzen, ESMO 2020 (60) & Denmark & 579 & $90 \mathrm{PS} \geq 2[16]$ \\
\hline
\end{tabular}

*, patients with known negative status for sensitizing EGFR mutations and ALK fusions. 
Table 3 Prospective studies evaluating PD-1/PD-L1 inhibition in the first-line setting of PS 2 patients

\begin{tabular}{|c|c|c|c|c|}
\hline Study & Country & Patients & PD-L1 status and drug & Main findings \\
\hline $\begin{array}{l}\text { Middleton, Lancet Resp Med 2020, } \\
\text { PePS2 (61) }\end{array}$ & & & & ORR $21 \%(n=5 ; 9-40)$ \\
\hline \multirow[t]{2}{*}{$\begin{array}{l}\text { Mark, Cancer Immunol } \\
\text { Immunother 2020, SAKK 19/17 (63) }\end{array}$} & Switzerland & 21 & PD-L1 $\geq 25 \%$, Durvalumab & $\begin{array}{l}13 \text { out of } 21 \text { treated patients died } \\
(62 \%)\end{array}$ \\
\hline & & & & $\begin{array}{l}\text { Seven deaths }(7 / 13 ; 54 \%) \text { observed } \\
\text { during the first five weeks }\end{array}$ \\
\hline \multirow{2}{*}{$\begin{array}{l}\text { Barlesi, WCLC 2019, CheckMate } \\
817 \text { (62) }\end{array}$} & & & & mPFS 3.6 months (2.8-5.4) \\
\hline & & & & mDOR 14.2 months (10.0-NR) \\
\hline
\end{tabular}

Data included in parenthesis indicate 95\% confidence interval. DCB, durable clinical benefit, i.e., lack of progression at the 18th week; ORR, objective response rate; mPFS, median progression-free survival; mOS, median overall survival; NR, not reached; mDOR, median duration of response.

Table 4 Studies dealing with chemo-immunotherapy combinations including poor PS patients

\begin{tabular}{|c|c|c|c|c|}
\hline Study & Country & PD-L1 status & Patients & Poor PS patients [\%] \\
\hline Tabah, ASCO 2020 (65) & USA & Any & 254 pembro + chemo & $34 \mathrm{PS}=2 / 3[13]$ \\
\hline Velcheti, ESMO 2020 (66) & USA & Any & $99 \geq 75$ y pembro + chemo & $13 \mathrm{PS}=2[13]$ \\
\hline Dudnik, ESMO 2020 (67) & Israel & $\geq 50 \%$ & 203 pembrolizumab & $63 \mathrm{PS} \geq 2[31]$ \\
\hline \multirow[t]{2}{*}{ Takumida, ESMO 2020 (68) } & Japan & $\geq 50 \%$ & 71 pembrolizumab & $17 \mathrm{PS} \geq 2[24]$ \\
\hline & & & 26 pembro + chemo & $4 \mathrm{PS} \geq 2[13]$ \\
\hline \multirow[t]{2}{*}{ Aggarwal, Clin Cancer Res 2020 (69) } & USA & $\geq 50 \%$ & 31 pembrolizumab & $8 \mathrm{PS}=2 ; 1 \mathrm{PS} \geq 3$ [29] \\
\hline & & 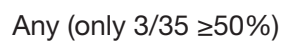 & 35 pembro + chemo & $1 \mathrm{PS}=2[3]$ \\
\hline
\end{tabular}

in two studies specifically reporting outcomes of PS 2 patients $(42,49)$. Pooling data into landmark PFS rates from six studies with available information $(28,29,31,38,44,45)$, it was estimated that $45 \%, 30 \%, 22 \%$ and $13 \%$ of the patients had not progressed at thee, six, 12 and 18 months, respectively (Table 7) (71-73).

With regard to PS $0-1$ patients, median PFS estimations ranged from around $5-6(31,35,44)$ to $10-11$ months
$(28,42,50)$ (Table 6). Landmark PFS values of good PS patients were available and pooled from five studies $(28,31,38,44,45)$. PFS-free rate at 3, 6, 12 and 18 months was $75 \%, 60 \%, 45 \%$ and $36 \%$, respectively (Table 7 ).

\section{Overall survival}

20 studies provided information on OS of poor PS patients, 16 only reporting their numbers and the comparison with 

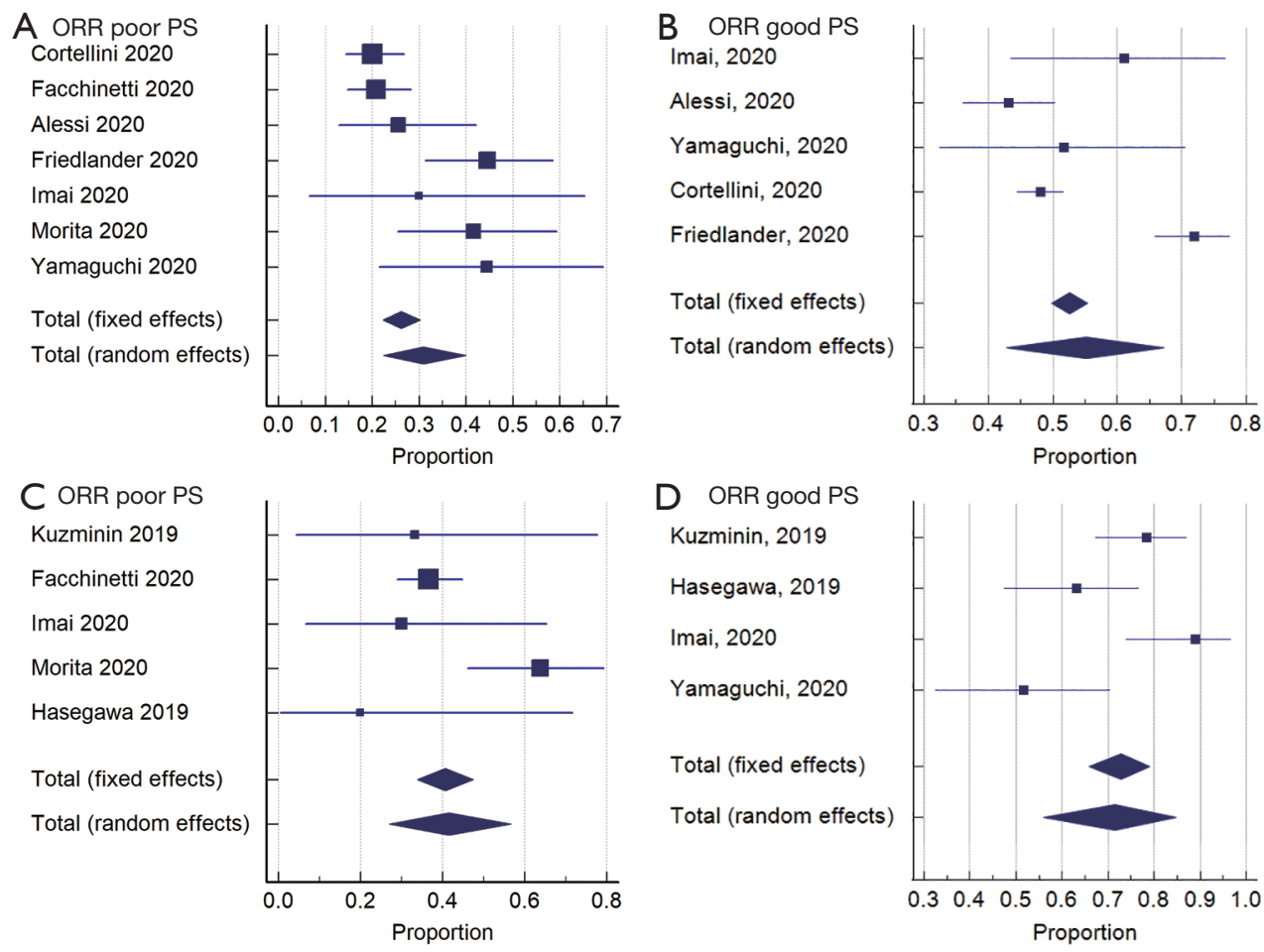

Figure 2 Meta-analysis of objective responses and disease control in patients with ECOG performance status $\geq 2$ (poor PS) and 0-1 (good PS) receiving pembrolizumab in retrospective studies. ORR, objective response rate; DCR, disease control rate.

PS 0-1 cases, while median PFS estimations for the poor PS group were provided in 14 studies (Table 8). Almost invariably, OS was statistically worse in poor PS patients compared to good PS ones, in the 17 studies reporting any survival information, with not significant trends only in report with a relative low number of PS $\geq 2$ cases (Table 8). Median OS ranged from less than 2 months in elderly patients (39) to approximately an 1 year, in the cohort of Mouritzen et al. (60). Six studies provided information for landmark OS estimations $(28,29,38,43-45)$. Pooling these data, $42 \%, 31 \%, 26 \%$ and $21 \%$ of the patients were alive six, 12,18 and 24 months since pembrolizumab start, respectively (Table 7).

In ECOG PS $0-1$ patients, median OS estimations ranged from 12.4 months in the study of Velcheti et al. (31) to approximately 20 months in other populations $(28,44,60)$ (Table 8). In several studies, the relatively short follow-up did not allow to report median OS for good PS patients. Pooling the data of five studies $(28,38,43-45)$, approximately $80 \%, 70 \%, 60 \%$ and $50 \%$ of patients were alive six, 12,18 and 24 months since pembrolizumab start (Table 7).

\section{"Very poor" PS patients}

Precise data on PS 3-4 patients have only been reported by Kano et al. (49) and by Inaba-Higashiyama et al. (53). In the first study, six out of 85 patients (7\%) started pembrolizumab with an ECOG PS of 3 or 4, achieving median PFS and OS of approximately 1 and 2 months, respectively (Tables 6,8). In their cohort of 250 patients, Inaba-Higashiyama et al. identified four cases with an ECOG PS of 3 (53). While three patients progressed rapidly to pembrolizumab, in one case with PD-L1 $=100 \%$ systemic disease response was achieved (Table 5).

\section{Pembrolizumab safety in the first-line setting of poor PS patients}

Cortellini et al. reported the toxicity outcomes of a large cohort of NSCLC patients receiving first-line pembrolozumab (30). An ECOG PS $\geq 2 \quad(n=174)$ was correlated with a lower incidence of immune-related adverse events (irAEs) (21.2\% compared to $35 \%$ of PS $0-1)$, likely due to the shorter exposure to pembrolizumab of poor PS patients. Similarly, no toxicity issue emerged in the PS 2 population reported by Facchinetti et al. (29). In their 
Table 5 Objective response rates and disease control rates in studies including poor PS patients

\begin{tabular}{|c|c|c|c|c|c|c|c|c|c|c|c|c|}
\hline Reference & Patients & $\begin{array}{l}\text { Poor PS } \\
\text { patients }\end{array}$ & \multicolumn{3}{|c|}{ ORR } & \multicolumn{3}{|c|}{ DCR } & \multicolumn{3}{|c|}{ PD } & $\begin{array}{l}\text { Statistics PS 0-1 vs. } \\
\text { poor PS, }(95 \% \mathrm{Cl})\end{array}$ \\
\hline $\begin{array}{l}\text { Imai, J Cancer Res } \\
\text { Clin Oncol } 2020 \text { (40) }\end{array}$ & $47 \geq 75 y$ & $\begin{array}{c}7 \mathrm{PS}=2 \\
3 \mathrm{PS}=3 \\
2 \mathrm{NE}\end{array}$ & NA & $61 \% *$ & $43 \%{ }^{*}$ & NA & $89 \% *$ & $43 \%{ }^{*}$ & NA & $11 \%{ }^{*}$ & $57 \% *$ & $\mathrm{P}=0.15 \mathrm{RR}, \mathrm{P}=0.03 \mathrm{DCR}$ \\
\hline $\begin{array}{l}\text { Morita, BMC Cancer } \\
2020(41)\end{array}$ & 205 & $\begin{array}{c}29 \mathrm{PS}=2 \\
6 \mathrm{PS}=3 \\
1 \mathrm{PS}=4\end{array}$ & NA & $55 \%$ & $42 \%$ & NA & $77 \%$ & $64 \%$ & NA & $23 \%$ & $36 \%$ & $\begin{array}{c}\text { Multivariate: OR } 1.44 \\
(0.57-3.59), P=0.4366 \\
\text { for response; } P=0.0832 \\
\text { within poor } P S \text { group, } \\
\text { trend towards lack of } \\
\text { response }\end{array}$ \\
\hline $\begin{array}{l}\text { Facchinetti, Eur J } \\
\text { Cancer } 2020 \text { (29) }\end{array}$ & 153 & $153 \mathrm{PS}=2$ & - & - & $21 \%$ & - & - & $37 \%$ & - & - & $63 \%$ & - \\
\hline $\begin{array}{l}\text { Cortellini, Cancer } \\
\text { Immunol Immunother } \\
2020 \text { (28) }\end{array}$ & 1026 & $\begin{array}{c}179 \mathrm{PS} \geq 2 \\
36 \mathrm{NE}\end{array}$ & NA & $48 \% *$ & $25 \% *$ & NA & NA & NA & NA & NA & NA & $\begin{array}{c}\mathrm{P}<0.0001 \text {, Multivariate: } \\
\text { OR } 2.60 \text { (1.73-3.91); } \\
\mathrm{P}<0.0001\end{array}$ \\
\hline $\begin{array}{l}\text { Alessi, J Immunother } \\
\text { Cancer } 2020 \text { (45) }\end{array}$ & 234 & $39 \mathrm{PS}=2$ & NA & $43 \%$ & $26 \%$ & NA & NA & NA & NA & NA & NA & $P=0.04$ \\
\hline $\begin{array}{l}\text { Friedlaender, Acta } \\
\text { Oncol } 2020(46)\end{array}$ & 302 & $56 \mathrm{PS}=2$ & NA & $72 \%$ & $45 \%$ & NA & NA & NA & NA & NA & NA & OR $0.31(0.17-0.57)$ \\
\hline $\begin{array}{l}\text { Inaba-Higashiyama, } \\
\text { Thorac Cancer } \\
2020 \text { (31) }\end{array}$ & 4 & $4 P S=3$ & - & - & $25 \%{ }^{\S}$ & - & - & $25 \%^{\S}$ & - & - & - & - \\
\hline
\end{tabular}

*, only TC-evaluated patients considered in calculating the rates (i.e., non evaluated patients are not included in the analyses). ${ }^{\S}$, Patient with PD-L1 =100\%. y, years; PS, performance status; NE, not evaluated; ORR, objective response rate; NA, not available; DCR, disease control rate; $\mathrm{PD}$, progressive disease; OR, odds ratio; $95 \% \mathrm{Cl}, 95 \%$ confidence interval.

cohort, Cavaille et al. reported that grade $\geq 3$ irAEs occurred in four of 41 patients, all of them with PS 2-3; two of them, registered with disease progression, were considered fatal events (43). No difference in pembrolizumab-related toxicity was reported in other studies according to ECOG PS status $(41,45)$.

\section{Prospective trials with anti-PD-1/PD-L1 agents for PS 2 NSCLC patients}

When dealing with prospective studies specifically testing immunotherapy in PS 2 patients (Table 3), diverse results were observed.

PePS2 was a phase 2 study enrolling PS 2 patients to 
Table 6 Progression-free survival outcomes in studies including poor PS patients

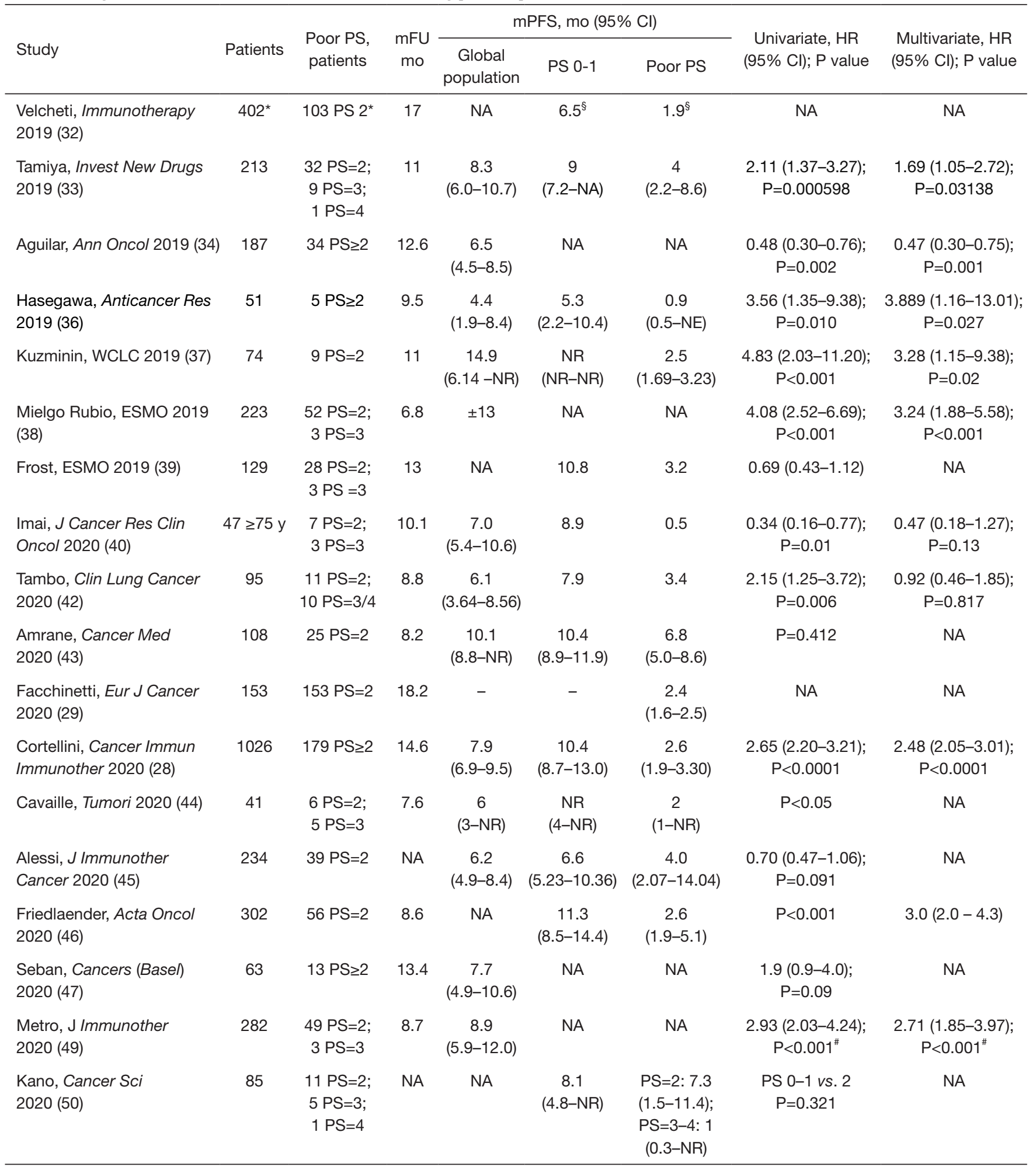

Table 6 (continued) 
Table 6 (continued)

\begin{tabular}{|c|c|c|c|c|c|c|c|c|}
\hline \multirow{2}{*}{ Study } & \multirow{2}{*}{ Patients } & \multirow{2}{*}{$\begin{array}{l}\text { Poor PS, } \\
\text { patients }\end{array}$} & \multirow{2}{*}{$\begin{array}{c}\mathrm{mFU} \\
\mathrm{mo}\end{array}$} & \multicolumn{3}{|c|}{ mPFS, mo $(95 \% \mathrm{Cl})$} & \multirow{2}{*}{$\begin{array}{c}\text { Univariate, HR } \\
(95 \% \mathrm{Cl}) ; \mathrm{P} \text { value }\end{array}$} & \multirow{2}{*}{$\begin{array}{l}\text { Multivariate, HR } \\
(95 \% \mathrm{Cl}) ; \mathrm{P} \text { value }\end{array}$} \\
\hline & & & & $\begin{array}{c}\text { Global } \\
\text { population }\end{array}$ & PS 0-1 & Poor PS & & \\
\hline $\begin{array}{l}\text { Yamaguchi, Sci Rep } \\
2020 \text { (51) }\end{array}$ & 48 & $18 \mathrm{PS}=2 / 3$ & 11.5 & 7.1 & 10.8 & 5.6 & $\begin{array}{c}1.64(0.77-3.40) \\
P=0.18\end{array}$ & NA \\
\hline $\begin{array}{l}\text { Ichihara, Lung Cancer } \\
2020 \text { (52) }\end{array}$ & 84 & $18 \mathrm{PS} \geq 2$ & NA & $\begin{array}{c}6.9 \\
(3.8-11.4)\end{array}$ & NA & NA & NA & $\begin{array}{c}2.21(1.15-4.28) ; \\
P=0.017\end{array}$ \\
\hline $\begin{array}{l}\text { Sakai, J Cancer Res Clin } \\
\text { Oncol } 2020 \text { (53) }\end{array}$ & 33 & $8 \mathrm{PS} \geq 2$ & 16.7 & & NA & & $\begin{array}{c}0.47(0.19-1.33) \\
P=0.15\end{array}$ & $\begin{array}{c}0.55(0.22-1.56) ; \\
P=0.25\end{array}$ \\
\hline
\end{tabular}

Table 7 Meta-analysis of survival rates at landmark time-points

\begin{tabular}{|c|c|c|c|c|c|c|}
\hline & \multicolumn{3}{|c|}{ Poor PS } & \multicolumn{3}{|c|}{ Good PS } \\
\hline 6-months PFS & 6 [162] & 0.30 & $0.27-0.35$ & 5 [930] & 0.60 & $0.58-0.63$ \\
\hline 6-months OS & 6 [175] & 0.42 & $0.37-0.47$ & 5 [986] & 0.81 & $0.79-0.83$ \\
\hline 12-months OS & $6[90]$ & 0.31 & $0.26-0.37$ & 5 [591] & 0.68 & $0.65-0.71$ \\
\hline 18-months OS & $5[47]$ & 0.26 & $0.20-0.34$ & 5 [270] & 0.58 & $0.53-0.62$ \\
\hline
\end{tabular}

receive pembrolizumab as a first $(n=24)$ or later $(n=36)$ treatment line, regardless of PD-L1 status (61). As stated by the Authors, the study was characterized by a rigorous definition of PS 2. Of note, PS 2 status had to be stable for at least two weeks before trial entry and no immunosuppressive drugs in the week preceding pembrolizumab start were allowed, implying that only PS 2 patients not requiring steroids were included. Indeed, out of 112 patients screened, 60 (54\%) started pembrolizumab treatment. The recording of Charlson comorbidity index scores represented an added value of this study. The majority of the patients $(90 \%)$ had a comorbidity index $\leq 10$ in a scale from 0 to 37 , where a metastatic solid tumor account for 6 points, age 60-69 and 70-79 for 2 and 3 points, respectively (with a median age of patients included in the study of 72 years) (74). The efficacy results sustain a wider use of pembrolizumab in this population, as durable clinical benefit (DCB, i.e., lack of progression at the $18^{\text {th }}$ week, the main efficacy outcome) occurred in $38 \%$ of first-line. As expected, responses and survival outcomes were progressively better when segmenting patients according PD-L1 expression. Paradoxically, response rate (31\% vs. 24\%) and median OS (10.4 vs. 7.9 months) were numerically better in the subsequent-line compared with first-line, with median PFS overlapping at approximately 4 months. The surprising results in the subsequent-lines group even outperformed the KEYNOTE-001 data in PS $0-1$, PD-L $1 \geq 1 \%$ patients (response rate $18 \%$, median 
Table 8 Overall survival outcomes in studies including poor PS patients

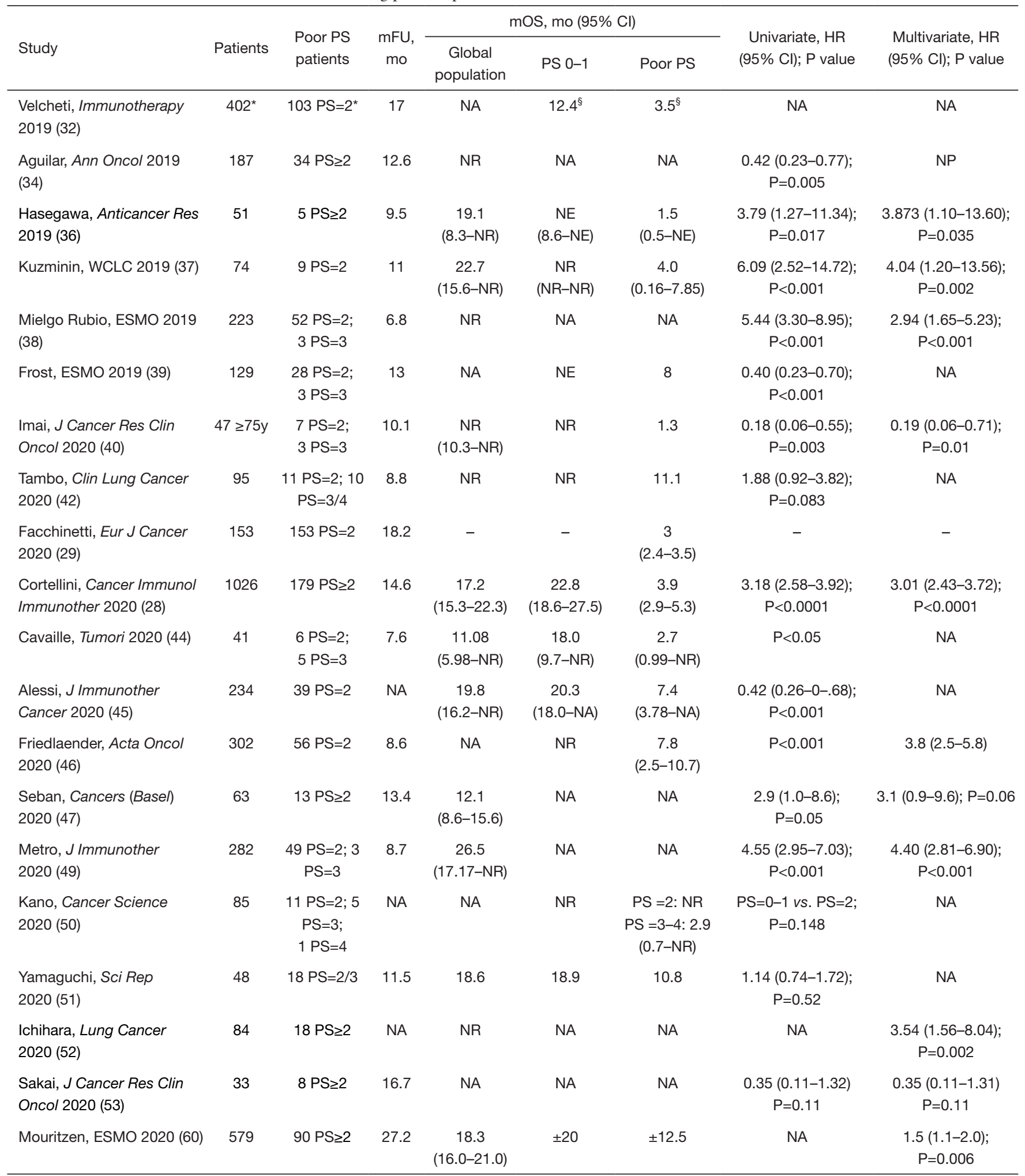

*, patients with known negative status for sensitizing EGFR mutations and ALK fusions. §, "Patient follow-up" in the study. y, years; PS, performance status; mFU, median follow-up; mo, months; NA, not available; mOS, median overall survival; 95\% Cl, 95\% confidence interval; NR, not reached; NE, not estimable; HR, hazard ratio. 
PFS and OS 3 and 9.3 months, respectively) (75). The evaluation of toxicity, co-primary end-point together with DCB, documented pembrolizumab was globally safe in this population. In addition to the limited patient number acknowledged by Authors, we deem that the extreme patient selection limits the generalization of the data obtained in PePS2 for the care of PS 2 NSCLC patients.

On the other hand indeed, Mark et al. recently reported the interim safety analysis of the phase 2 SAKK 19/17 trial, enrolling PS 2 NSCLC patients with a PD-L1 $\geq 25 \%$ to receive durvalumab. This unplanned analysis has been solicited by the early death rate observed among the first 21 treated patients (63). Relevant exclusion criteria were the presence of active brain metastases and the concomitant treatment with steroids at the dose of $>10 \mathrm{mg}$ daily of prednisone or equivalent. At the moment of data analysis, 13 out of 21 treated patients had died, one for a treatmentrelated colonic perforation (after prolonged disease response), while 12 for disease progression. Of note, in seven cases death occurred within the first five weeks since duvalumab initiation. The presence of significant burden of symptoms (especially respiratory) at baseline has been suggested as a clinical marker of dismal outcomes to the anti-PD-L1 agent in this population, and the trials have been emended to exclude patients with grade $\geq 3$ dyspnea and to incorporate the confirmation of the PS 2 by a second physician.

CheckMate 817 trial enrolled 589 advanced NSCLC patients to receive upfront nivolumab and ipilimumab combination (62). A specific cohort (A1) was dedicated to special populations, including ECOG PS 2 patients $(\mathrm{n}=139)$. ORR was $36 \%$ and $19 \%$ in cohort A (ECOG PS $0-1$ patients without meaningful comorbidities) and PS 2 patients, respectively, median PFS 5.8 (95\% CI: 4.5-7.6) and $3.6(2.8-5.4)$ months, with $35 \%$ and $25 \%$ of the patients not progressing at one year since treatment start, respectively.

\section{First-line chemo-immunotherapy combinations in poor PS NSCLC patients}

Across three retrospective studies describing the preliminary results of chemo-immunotherapy combinations in real-life settings, the proportion of poor PS patients was estimated at $10-13 \%$, also including a cohort dealing only with elderly patients (64-66) (Table 3). Three additional series reported data regarding the current scenario of first-line
NSCLC treatment, represented by the differential choice of pembrolizumab monotherapy or of pembrolizumabchemotherapy associations when dealing with PD-L1 $\geq 50 \%$ tumors (67-69) (Table 3). Still with the limitation of an interpretation of retrospective observations, it is remarkable that, among the population receiving chemoimmuno combinations, poor PS patients were far less represented $(-50 \%)$ compared to the one treated with pembrolizumab only $(67,68)$. Even more representative, in the study by Aggarwal et al., out the 31 patients receiving pembrolizumab, nine (29\%) had a poor PS, compared to one PS 2 (3\%) patient among the 35 candidates to chemoimmunotherapy associations (69). These observations, still initial and derived from retrospective studies, suggest a potential preference of treating physicians towards a safer therapeutic approach in PS 2 NSCLC patients, privileging mono-immunotherapy to combinations with cytotoxic agents.

\section{Discussion}

Treatment strategies involving immunotherapy have revolutionized the approach to advanced NSCLC in the first-line setting. Whereas the benefit observed in clinical trials can be mirrored in clinical practice is still a matter of debate. While no sufficient information is available to discuss the role of chemo-immunotherapy combinations in real-life scenarios, retrospective data sustain the utilization of single-agent pembrolizumab in good PS patients suffering from PD-L1 $\geq 50 \%$ NSCLC, while the benefit generated in the poor PS population (accounting for the $19 \%$ of the patients) still appear dismal. Prospective studies are enrolling PS 2 patients regardless of PD-L1 status (NCT02879617) or PS $2-3$ patients with PD-L1 $\geq 25 \%$ (NCT04108026 "SAVIMMUNE") to receive durvalumab. Performing prospective trials and observational studies is indeed of pivotal relevance in this setting, as the global quality of the data included in the present analysis can be questioned, acknowledging that almost all the studies are retrospective.

The divergent outcomes observed in PePS2 and SAKK 19/17 (acknowledging these latter are preliminary) sustain how the definition of PS 2 is crucial for including patients in dedicated clinical trials, and also to report outcomes of poor PS patients included in retrospective studies. Narrowing the criteria in order to obtain a relatively fit population of PS 2 NSCLC patients could nevertheless limit the extrapolation of the data themselves for the 
application in the clinical practice. Acknowledging the practicality of ECOG (and Karnofsky) scales in assessing PS, Scott et al. recently discusses the novel frontiers of PS measurement, encompassing digital tools worn by patients, registering physiological and mobility-related data whose integration can better define the fitness of each subject (76). Increasing the accuracy and objectivity in assessing PS would hopefully contribute to run clinical trials whose results can be replicate in the daily life, and to address patients to the most adequate treatment according to initial fitness.

The availability of both single-agent pembrolizumab and chemo-immunotherapy options in the first-line treatment of NSCLC, especially if PD-L $1 \geq 50 \%$ raises the question about which can be the best upfront therapy. Patient selection towards one strategy or the other is not the objective of the present review. Not limited to PS $\geq 2$ patients, the precise evaluation of PD-L1 expression levels can guide on treatment choices, as the higher levels are correlated to the best outcomes when immunotherapy is administered both as single agent (33) and as combined with chemotherapy $(2,3)$.

Dealing precisely with poor PS patients, the dismal outcomes globally observed with pembrolizumab monotherapy could sustain the implementation of combination strategies in patients who can afford them. In particular, albeit it emerged from a single, retrospective study led by our group, the reason conditioning a PS 2 strongly correlated with the benefit driven from first-line pembrolizumab, with comorbidity-related cases of poor PS still obtaining satisfactory results compared to patients whose fitness was undermined by disease burden itself. Acknowledging that, especially in NSCLC, comorbidities, disease aggressiveness, age and global frailty can concur to a poor PS, single agent pembrolizumab can be proposed to PD-L $1 \geq 50 \%$ cases whose PS 2 is mainly determined by comorbidities. On the other hand, chemo-immunotherapy combinations could be proposed to poor PS NSCLC patients with high disease burden, likely to tolerate them and reasonably needing a combined approach in order to contrast a rapid evolution of the disease. Aiming to obtain the larger effect against aggressive tumors, the synergistic effect of combinations of chemo- and immunotherapy could be likely obtained also with adapted doses and schema of cytotoxic agents. Albeit their trial was not limited to previously untreated patients, Bonomi et al. reported interesting preliminary data in this sense (77). Without taking into account PD-L1 status, PS patients were randomized to receive first-line pembrolizumab either as mono-therapy $(\mathrm{n}=10)$ or combined with weekly, low-dose carboplatin (AUC 1) and paclitaxel $\left(25 \mathrm{mg} / \mathrm{m}^{2}\right)(\mathrm{n}=10)$. Albeit long-term readouts of activity and efficacy are expected, responses were observed in two and seven cases, with additional four and two patients obtaining disease stabilization in the respective treatment arms, with no toxicity warnings.

Eagerly waiting for data on this subject, the very initial experiences gathered in Table 3, only reporting the proportion of poor PS patients addressed to chemoimmunotherapy, suggests that oncologists can reasonably hesitate to proposing such regimens to PS 2-3 patients. Registering the outcomes of carboplatin-based regimens associated with PD-1/PD-L1 in PS 2 NSCLC patients is the object of NCT04253964 and NCT04262869 studies, with pembrolizumab and durvalumab as ICIs, respectively. In the clinical trial NCT04297605, single agent chemotherapy (pemetrexed or nab-paclitaxel) is associated to pembrolizumab for the first-line treatment of PS 2 NSCLC, regardless of PD-L1 status. The combination of nivolumab and ipilimumab, already evaluated for PS 2 patients in CheckMate 817, have been compared to carboplatin-based chemotherapy in NCT03351361 (eNERGY), including both PS 2 and elderly (>70 years-old and PS 0-1) NSCLC patients.

In conclusion, the evolution in NSCLC treatment provided by immunotherapy is still limited to good PS patients. Prospective evidence, both observational and interventional, are eagerly awaited to define the best therapeutic strategies in poor PS patients, usually neglected in clinical trials but accounting for a significant proportion of the global population of NSCLC, as in our analysis $19 \%$ of the patients who receive first-line pembrolizumab had a $\mathrm{PS} \geq 2$.

\section{Acknowledgments}

Funding: None.

\section{Footnote}

Provenance and Peer Review: This article was commissioned by the Guest Editors (Jordi Remon and Benjamin Besse) for the series "Immunotherapy in other thoracic malignancies and uncommon populations" published in Translational Lung Cancer Research. The article has undergone external peer review. 
Reporting Checklist: The authors have completed the PRISMA reporting checklist. Available at http://dx.doi. org/10.21037/tlcr-21-15

Peer Review File: Available at http://dx.doi.org/10.21037/ tlcr-21-15

Conflicts of Interest: All authors have completed the ICMJE uniform disclosure form (available at http://dx.doi. org/10.21037/tlcr-21-15). The series "Immunotherapy in other thoracic malignancies and uncommon populations" was commissioned by the editorial office without any funding or sponsorship. MT serves as an unpaid editorial board member of Translational Lung Cancer Research from Dec 2014 to Nov 2021. FF reports personal fees from BMS, personal fees from Roche, outside the submitted work. MDM reports personal fees from Astra-Zeneca, personal fees from Pfizer, personal fees from BMS, personal fees from MSD, personal fees from Eisai, personal fees from Janssen, personal fees from Astellas, personal fees from Takeda, grants from Tesaro-GSK, outside the submitted work. MT reports grants and personal fees from Astra-Zeneca, grants and personal fees from Boehringer Ingelheim, grants from Pfizer, personal fees from Eli-Lilly, personal fees from BMS, grants and personal fees from Novartis, grants and personal fees from Roche, grants and personal fees from MSD, grants from Otsuka, grants from Pierre Fabre, outside the submitted work. The authors have no other conflicts of interest to declare.

Ethical Statement: The authors are accountable for all aspects of the work in ensuring that questions related to the accuracy or integrity of any part of the work are appropriately investigated and resolved.

Open Access Statement: This is an Open Access article distributed in accordance with the Creative Commons Attribution-NonCommercial-NoDerivs 4.0 International License (CC BY-NC-ND 4.0), which permits the noncommercial replication and distribution of the article with the strict proviso that no changes or edits are made and the original work is properly cited (including links to both the formal publication through the relevant DOI and the license). See: https://creativecommons.org/licenses/by-nc-nd/4.0/.

\section{References}

1. Reck M, Rodríguez-Abreu D, Robinson AG, et al.
Pembrolizumab versus Chemotherapy for PD-L1Positive Non-Small-Cell Lung Cancer. N Engl J Med 2016;375:1823-33.

2. Gandhi L, Rodríguez-Abreu D, Gadgeel S, et al. Pembrolizumab plus Chemotherapy in Metastatic NonSmall-Cell Lung Cancer. N Engl J Med 2018;378:2078-92.

3. Paz-Ares L, Luft A, Vicente D, et al. Pembrolizumab plus Chemotherapy for Squamous Non-Small-Cell Lung Cancer. N Engl J Med 2018;379:2040-51.

4. Reck M, Mok TSK, Nishio M, et al. Atezolizumab plus bevacizumab and chemotherapy in non-small-cell lung cancer (IMpower150): key subgroup analyses of patients with EGFR mutations or baseline liver metastases in a randomised, open-label phase 3 trial. Lancet Respir Med 2019;7:387-401.

5. Reck M, Ciuleanu TE, Dols MC, et al. Nivolumab (NIVO) + ipilimumab (IPI) + 2 cycles of platinum-doublet chemotherapy (chemo) vs 4 cycles chemo as first-line (1L) treatment (tx) for stage IV/recurrent non-small cell lung cancer (NSCLC): CheckMate 9LA. J Clin Oncol 2020;38:9501.

6. Ackermann CJ, Reck M, Paz-Ares L, et al. First-line immune checkpoint blockade for advanced non-small-cell lung cancer: Travelling at the speed of light. Lung Cancer 2019;134:245-53.

7. Abi Jaoude J, Kouzy R, Mainwaring W, et al. Performance Status Restriction in Phase III Cancer Clinical Trials. J Natl Compr Canc Netw 2020;18:1322-6.

8. Oken MM, Creech RH, Tormey DC, et al. Toxicity and response criteria of the Eastern Cooperative Oncology Group. Am J Clin Oncol 1982;5:649-55.

9. Capewell S, Sudlow MF. Performance and prognosis in patients with lung cancer. The Edinburgh Lung Cancer Group. Thorax 1990;45:951-6.

10. Kawaguchi T, Takada M, Kubo A, et al. Performance status and smoking status are independent favorable prognostic factors for survival in non-small cell lung cancer: a comprehensive analysis of 26,957 patients with NSCLC. J Thorac Oncol 2010;5:620-30.

11. Kato Y, Hosomi Y, Watanabe K, et al. Impact of clinical features on the efficacy of osimertinib therapy in patients with T790M-positive non-small cell lung cancer and acquired resistance to epidermal growth factor receptor tyrosine kinase inhibitors. J Thorac Dis 2019;11:2350-60.

12. Rittberg R, Green S, Aquin T, et al. Effect of Hospitalization During First Chemotherapy and 
Performance Status on Small-cell Lung Cancer Outcomes. Clin Lung Cancer 2020;21:e388-404.

13. Karnofsky DA. The clinical evaluation of chemotherapeutic agents in cancer. Evaluation of Chemotherapeutic Agents 1949;191-205.

14. Lilenbaum RC, Cashy J, Hensing TA, et al. Prevalence of poor performance status in lung cancer patients: implications for research. J Thorac Oncol 2008;3:125-9.

15. Gajra A, Marr AS, Ganti AK. Management of patients with lung cancer and poor performance status. J Natl Compr Canc Netw 2014;12:1015-25.

16. Iwama E, Goto Y, Murakami H, et al. Survival Analysis for Patients with ALK Rearrangement-Positive Non-Small Cell Lung Cancer and a Poor Performance Status Treated with Alectinib: Updated Results of Lung Oncology Group in Kyushu 1401. Oncologist 2020;25:306-e618.

17. Planchard D, Popat S, Kerr K, et al. Metastatic non-small cell lung cancer: Ann Oncol Clinical Practice Guidelines for diagnosis, treatment and follow-up. Ann Oncol 2018;29:iv192-237.

18. Ettinger DS, Wood DE, Aggarwal C, et al. Non-small cell lung cancer, version 1.2020: Featured updates to the NCCN guidelines. J Natl Compr Canc Netw 2019;17:1464-72.

19. Ardizzoni A, Azevedo S, Rubio-Viqueira B, et al. Primary results from TAIL: a global single-arm safety study of atezolizumab monotherapy in a diverse population of patients with previously treated advanced non-small cell lung cancer. J Immunother Cancer 2021;9:e001865.

20. Felip E, Ardizzoni A, Ciuleanu T, et al. CheckMate 171: A phase 2 trial of nivolumab in patients with previously treated advanced squamous non-small cell lung cancer, including ECOG PS 2 and elderly populations. Eur J Cancer 2020;127:160-72.

21. Spigel DR, McCleod M, Jotte RM, et al. Safety, Efficacy, and Patient-Reported Health-Related Quality of Life and Symptom Burden with Nivolumab in Patients with Advanced Non-Small Cell Lung Cancer, Including Patients Aged 70 Years or Older or with Poor Performance Status (CheckMate 153). J Thorac Oncol 2019;14:1628-39.

22. Juergens R, Chu Q, Rothenstein J, et al. P2.07-029 CheckMate 169: Safety/Efficacy of Nivolumab in Canadian Pretreated Advanced NSCLC (including Elderly and PS 2) Patients. J Thorac Oncol 2017;12:S2426-7.
23. Facchinetti F, Veneziani M, Buti S, et al. Clinical and hematologic parameters address the outcomes of nonsmall-cell lung cancer patients treated with nivolumab. Immunotherapy 2018;10:681-94.

24. Molinier O, Audigier-Valette C, Cadranel J, et al. OA 17.05 IFCT-1502 CLINIVO: Real-Life Experience with Nivolumab in 600 Patients (Pts) with Advanced NonSmall Cell Lung Cancer (NSCLC). J Thorac Oncol 2017;12:S1793.

25. Barlesi F, Dixmier A, Debieuvre D, et al. Effectiveness and safety of nivolumab in the treatment of lung cancer patients in France: preliminary results from the real-world EVIDENS study. Oncoimmunology 2020;9:1744898.

26. Dall'Olio FG, Maggio I, Massucci M, et al. ECOG performance status $\geq 2$ as a prognostic factor in patients with advanced non small cell lung cancer treated with immune checkpoint inhibitors-A systematic review and meta-analysis of real world data. Lung Cancer 2020;145:95-104.

27. Moher D, Liberati A, Tetzlaff J, et al. Preferred reporting items for systematic reviews and meta-analyses: the PRISMA statement. PLoS Med 2009;6:e1000097.

28. Cortellini A, Tiseo M, Banna GL, et al. Clinicopathologic correlates of first-line pembrolizumab effectiveness in patients with advanced NSCLC and a PD-L1 expression of $\geq 50$. Cancer Immunol Immunother 2020;69:2209-21.

29. Facchinetti F, Mazzaschi G, Barbieri F, et al. First-line pembrolizumab in advanced non-small cell lung cancer patients with poor performance status. Eur J Cancer 2020;130:155-67.

30. Cortellini A, Friedlaender A, Banna GL, et al. Immunerelated Adverse Events of Pembrolizumab in a Large Real-world Cohort of Patients With NSCLC With a PD-L1 Expression $\geq 50 \%$ and Their Relationship With Clinical Outcomes. Clin Lung Cancer 2020;21: 498-508.e2.

31. Velcheti V, Chandwani S, Chen X, et al. First-line pembrolizumab monotherapy for metastatic PD-L1positive NSCLC: real-world analysis of time on treatment. Immunotherapy 2019;11:889-901.

32. Tamiya M, Tamiya A, Hosoya K, et al. Efficacy and safety of pembrolizumab as first-line therapy in advanced nonsmall cell lung cancer with at least 50\% PD-L1 positivity: a multicenter retrospective cohort study (HOPE-001). Invest New Drugs 2019;37:1266-73.

33. Aguilar EJ, Ricciuti B, Gainor JF, et al. Outcomes to 
first-line pembrolizumab in patients with non-small-cell lung cancer and very high PD-L1 expression. Ann Oncol 2019;30:1653-9.

34. Edahiro R, Kanazu M, Kurebe H, et al. Clinical outcomes in non-small cell lung cancer patients with an ultra-high expression of programmed death ligand-1 treated using pembrolizumab as a first-line therapy: A retrospective multicenter cohort study in Japan. PLoS One 2019;14:e0220570.

35. Hasegawa T, Yanagitani N, Utsumi H, et al. Association of High Neutrophil-to-Lymphocyte Ratio With Poor Outcomes of Pembrolizumab Therapy in High-PD-L1expressing Non-small Cell Lung Cancer. Anticancer Res 2019;39:6851-7.

36. Kuzminin A, Minatta N, Tsou F, et al. First line treatment with pembrolizumab in patients with non-small cell lung cancer and PD-L1 tumor proportion score (TPS) $\geq 50 \%$ : real-world study in Argentina. J Thorac Oncol 2019;14:S589-590.

37. Rubio XM, Garcia MEO, Moyano MS, et al. Predictive model for survival in advanced non-small cell lung cancer (NSCLC) treated with frontline pembrolizumab. Ann Oncol 2019;30:v514.

38. Frost N, Kollmeier J, Pultermann D, et al. Pembrolizumab as first-line treatment in NSCLC with PD-L1 $\geq 50 \%$ : Real life results from an all-comer population. Ann Oncol 2019;30:v615.

39. Imai H, Wasamoto S, Yamaguchi O, et al. Efficacy and safety of first-line pembrolizumab monotherapy in elderly patients (aged $\geq 75$ years) with non-small cell lung cancer. J Cancer Res Clin Oncol 2020;146:457-66.

40. Morita M, Tamiya M, Fujimoto D, et al. Prediction of patients with a tumor proportion score $>50 \%$ who do not respond to first-line monotherapy with pembrolizumab. BMC Cancer 2020;20:93.

41. Tambo Y, Sone T, Shibata K, et al. Real-World Efficacy of First-Line Pembrolizumab in Patients With Advanced or Recurrent Non-Small-Cell Lung Cancer and High PD-L1 Tumor Expression. Clin Lung Cancer 2020;21:e366-79.

42. Amrane K, Geier M, Corre R, et al. First-line pembrolizumab for non-small cell lung cancer patients with PD-L1 $\geq 50 \%$ in a multicenter real-life cohort: The PEMBREIZH study. Cancer Med 2020;9:2309-16.

43. Cavaille F, Peretti M, Garcia ME, et al. Real-world efficacy and safety of pembrolizumab in patients with nonsmall cell lung cancer: a retrospective observational study. Tumori 2021;107:32-8.
44. Alessi JV, Ricciuti B, Jiménez-Aguilar E, et al. Outcomes to first-line pembrolizumab in patients with PD-L1-high ( $\geq 50 \%$ ) non-small cell lung cancer and a poor performance status. J Immunother Cancer 2020;8:e001007.

45. Friedlaender A, Metro G, Signorelli D, et al. Impact of performance status on non-small-cell lung cancer patients with a PD-L1 tumour proportion score $\geq 50 \%$ treated with front-line pembrolizumab. Acta Oncol 2020;59:1058-63.

46. Seban RD, Assié JB, Giroux-Leprieur E, et al. Association of the Metabolic Score Using Baseline FDG-PET/CT and dNLR with Immunotherapy Outcomes in Advanced NSCLC Patients Treated with First-Line Pembrolizumab. Cancers (Basel) 2020;12:2234.

47. Banna GL, Signorelli D, Metro G, et al. Neutrophil-tolymphocyte ratio in combination with $\mathrm{PD}-\mathrm{L} 1$ or lactate dehydrogenase as biomarkers for high PD-L1 non-small cell lung cancer treated with first-line pembrolizumab. Transl Lung Cancer Res 2020;9:1533-42.

48. Metro G, Banna GL, Signorelli D, et al. Efficacy of Pembrolizumab Monotherapy in Patients With or Without Brain Metastases From Advanced Non-Small Cell Lung Cancer With a PD-L1 Expression $\geq 50 \%$. J Immunother 2020;43:299-306.

49. Kano H, Ichihara E, Harada D, et al. Utility of immune checkpoint inhibitors in non-small-cell lung cancer patients with poor performance status. Cancer Sci 2020;111:3739-46.

50. Yamaguchi O, Kaira K, Hashimoto K, et al. Tumor metabolic volume by $18 \mathrm{~F}-\mathrm{FDG}-\mathrm{PET}$ as a prognostic predictor of first-line pembrolizumab for NSCLC patients with PD-L1 $\geq$ 50. Sci Rep 2020;10:14990.

51. Ichihara $\mathrm{E}$, Harada $\mathrm{D}$, Inoue $\mathrm{K}$, et al. The impact of body mass index on the efficacy of anti-PD-1/PD-L1 antibodies in patients with non-small cell lung cancer. Lung Cancer 2020;139:140-5.

52. Sakai T, Udagawa H, Matsumoto S, et al. Morphological, immune and genetic features in biopsy sample associated with the efficacy of pembrolizumab in patients with nonsquamous non-small cell lung cancer. J Cancer Res Clin Oncol 2021;147:1227-37.

53. Inaba-Higashiyama R, Yoshida T, Jo H, et al. Clinical outcomes of pembrolizumab therapy in advanced-NSCLC patients with poor performance status $(\geq 3)$ and high $\mathrm{PD}$ L1 expression (TPS $\geq 50 \%$ ): A case series. Thorac Cancer 2020;11:3618-21.

54. Yamaguchi O, Kaira K, Shinomiya S, et al. Pre-existing 
interstitial lung disease does not affect prognosis in nonsmall cell lung cancer patients with PD-L1 expression $\geq 50 \%$ on first-line pembrolizumab. Thorac Cancer 2021;12:304-13.

55. Wakuda K, Yabe M, Kodama H, et al. Efficacy of pembrolizumab in patients with brain metastasis caused by previously untreated non-small cell lung cancer with high tumor PD-L1 expression. Lung Cancer 2021;151:60-8.

56. Sehgal K, Bindal P, Koshy AG, et al. Effect of performance status on survival with pembrolizumab monotherapy in advanced non-small cell lung cancer (NSCLC). J Clin Oncol 2020;38:9533.

57. Pilotto S, Trestini I, Sperduti I, et al. 1831P Role of body composition (bc) in advanced non-small cell lung cancer (NSCLC) patients receiving first-line pembrolizumab (pembro). Ann Oncol 2020;31:S1054.

58. Lobefaro R, Viscardi G, Di Liello R, et al. 1329P Immune checkpoint inhibitors in advanced NSCLC patients with poor performance status: The role of clinical-pathological variables and inflammatory biomarkers in a real world experience. Ann Oncol 2020;31:S856-7.

59. Lester J, Escriu C, Khan S, et al. 1379P Real-world (RW) clinical outcomes of patients with metastatic non-small cell lung cancer (mNSCLC) in the United Kingdom. Ann Oncol 2020;31:S878-9.

60. Mouritzen M, Bjoernhart B, Poehl M, et al. 1334P Real word experience with first-line immunotherapy in advanced non-small cell lung cancer patients in a Danish nationwide cohort. Ann Oncol 2020;31:S858.

61. Middleton G, Brock K, Savage J, et al. Pembrolizumab in patients with non-small-cell lung cancer of performance status 2 (PePS2): a single arm, phase 2 trial. Lancet Respir Med 2020;8:895-904.

62. Frontera OA, Fontecedro AC. OA04.02 CheckMate 817: First-Line Nivolumab + Ipilimumab in Patients with ECOG PS 2 and Other Special Populations with Advanced NSCLC. J Thorac Oncol 2019;14:S214-5.

63. Mark M, Froesch P, Eboulet EI, et al. SAKK 19/17: safety analysis of first-line durvalumab in patients with PD-L1 positive, advanced nonsmall cell lung cancer and a performance status of 2. Cancer Immunol Immunother 2021;70:1255-62.

64. Clark J, Ricciuti B, Bolina A, et al. Influence of antibiotic therapy (ATB) on oncological outcomes of metastatic non-small cell lung cancer (mNSCLC) patients treated with chemo-immunotherapy (CIT). J Clin Oncol 2020;38:3080.

65. Tabah A, Huggar D, Kish J, et al. Real-world outcomes of pembrolizumab plus carboplatin plus paclitaxel or nabpaclitaxel in non-small cell lung cancer (NSCLC). J Clin Oncol 2020;38:e21717.

66. Velcheti V, Hu X, Chen X, et al. 1328P Clinical outcomes of pembrolizumab plus chemotherapy in non-squamous metastatic NSCLC patients aged 75 years or older at US oncology practices. Ann Oncol 2020;31:S856.

67. Dudnik E, Moskovitz M, Rottenberg Y, et al. Pembrolizumab as a monotherapy $(\mathrm{P})$ or in combination with platinum-based chemotherapy (PCT) in advanced non-small cell lung cancer (aNSCLC) with PD-L1 tumour proportion score (TPS) $\geq 50 \%$ : A realworld data (Israeli Lung Cancer Group). Ann Oncol 2020;31:S854.

68. Takumida H, Horinouchi H, Masuda K, et al. 1327P Benchmarking the efficacy and safety of pembrolizumab plus chemotherapy to pembrolizumab monotherapy: A consecutive analysis of NSCLC patients with high PD-L1 expression. Ann Oncol 2020;31:S855-6.

69. Aggarwal C, Thompson JC, Chien AL, et al. Baseline Plasma Tumor Mutation Burden Predicts Response to Pembrolizumab-based Therapy in Patients with Metastatic Non-Small Cell Lung Cancer. Clin Cancer Res 2020;26:2354-61.

70. Ferrara R, Pilotto S, Caccese M, et al. Do immune checkpoint inhibitors need new studies methodology? J Thorac Dis 2018;10:S1564-80.

71. VassarStats: Website for Statistical Computation. Available online: http://vassarstats.net/prop1.html

72. Newcombe RG. Two-sided confidence intervals for the single proportion: comparison of seven methods. Stat Med 1998; 17:857-72.

73. Wilson EB. Probable Inference, the Law of Succession, and Statistical Inference. J Am Stat Assoc 1927;22:209-12.

74. Charlson Comorbidity Index (CCI). Available online: https://www.mdcalc.com/charlsoncomorbidity-index-cci

75. Garon EB, Rizvi NA, Hui R, et al. Pembrolizumab for the Treatment of Non-Small-Cell Lung Cancer. N Engl J Med 2015;372:2018-28.

76. Scott JM, Stene G, Edvardsen E, et al. Performance Status in Cancer: Not Broken, But Time for an Upgrade? J Clin 
Oncol 2020;38:2824-9.

77. Bonomi M, Ahmed T, Addo S, Kooshki M, Palmieri

D, Levine BJ, et al. Circulating immune biomarkers as predictors of the response to pembrolizumab and weekly low dose carboplatin and paclitaxel in NSCLC and poor PS: An interim analysis. Oncol Lett 2019;17:1349-56.
Cite this article as: Facchinetti F, Di Maio M, Perrone F, Tiseo M. First-line immunotherapy in non-small cell lung cancer patients with poor performance status: a systematic review and meta-analysis. Transl Lung Cancer Res 2021;10(6):2917-2936. doi: $10.21037 /$ tlcr-21-15 


\section{Supplementary}

Table S1 Studies on first-line pembrolizumab in patients with PD-L1 $\geq 50 \%$, including both good and poor PS NSCLC patients, allowing the calculation of proportion of poor PS patients

Study

Velcheti, Immunotherapy 2019 (32)

Tamiya, Invest New Drugs 2019 (33)

Aguilar, ESMO 2019 (34)

Edahiro, Plos One 2019 (35)

Hasegawa, Anticancer Res 2019 (36)

Kuzminin, WCLC 2019 (37)

Mielgo Rubio, ESMO 2019 (38)

Frost, ESMO 2019 (39)

Imai, J Cancer Res Clin Oncol 2020 (40)

Morita, BMC Cancer 2020 (41)

Tambo, Clin Lung Cancer 2020 (42)

Amrane, Cancer Med 2020 (43)

Cortellini, Cancer Immunol Immunother 2020 (30)

Cavaille, Tumori 2020 (44)

Alessi, J Immunother Cancer 2020 (45)

Friedlaender, Acta Oncol 2020 (46)

Seban, Cancers 2020 (47)

Banna, Transl Lung Cancer Res 2020 (48)

Metro, J Immunother 2020 (49)

Kano, Cancer Science 2020 (50)

Yamaguchi, Sci Rep 2020 (51)

Ichihara, Lung Cancer 2020 (52)

Sakai, J Cancer Res Clin Oncol 2020 (53)

Yamaguchi, Thorac Cancer 2020 (54)

Wakuda, Lung Cancer 2020 (55)

Sehgal, ASCO 2020 (56)

Pilotto, ESMO 2020 (57)

Lobefaro, ESMO 2020 (58)

Lester, ESMO 2020 (59)

Mouritzen, ESMO 2020 (60)
Table S2 Studies included in the meta-analysis

Study

Velcheti, Immunotherapy 2019 (32)

Tamiya, Invest New Drugs 2019 (33)

Hasegawa, Anticancer Res 2019 (36)

Kuzminin, WCLC 2019 (37)

Frost, ESMO 2019 (39)

Imai, J Cancer Res Clin Oncol 2020 (40)

Morita, BMC Cancer 2020 (41)

Tambo, Clin Lung Cancer 2020 (42)

Amrane, Cancer Med 2020 (43)

Facchinetti, Eur J Cancer 2020 (29)

Cortellini, Cancer Immunol Immunother 2020 (30)

Cavaille, Tumori 2020 (44)

Alessi, J Immunother Cancer 2020 (45)

Friedlaender, Acta Oncol 2020 (46)

Kano, Cancer Science 2020 (50)

Yamaguchi, Sci Rep 2020 (51)

Inaba-Higashiyama, Thorac Cancer 2020 (31)

Mouritzen, ESMO 2020 (60) 


\begin{tabular}{|l|l|r|r|r|}
\hline Meta-analysis: proportion & & & \\
\hline
\end{tabular}

Test for heterogeneity

\begin{tabular}{|l|l|}
\hline$Q$ & 21.6393 \\
\hline DF & 6 \\
\hline Significance level & $\mathrm{P}=0.0014$ \\
\hline $\mathrm{I}^{2}$ (inconsistency) & $72.27 \%$ \\
\hline $95 \% \mathrm{Cl}$ for $\mathrm{I}^{2}$ & 40.07 to 87.17 \\
\hline
\end{tabular}

Figure S1 Meta-analysis of objective response for PS $\geq 2$ patients. Q, Cochran's heterogeneity statistic; DF, degrees of freedom

\begin{tabular}{|c|c|c|c|c|c|}
\hline \multicolumn{6}{|l|}{ Meta-analysis: proportion } \\
\hline Variable for studies & \multicolumn{5}{|l|}{ Author } \\
\hline Variable for total number of cases & \multicolumn{5}{|l|}{$\mathrm{N}$} \\
\hline Variable for number of positive cases & \multicolumn{5}{|l|}{ Disease control } \\
\hline \multirow[t]{2}{*}{ Study } & \multirow[t]{2}{*}{ Sample size } & \multirow[t]{2}{*}{ Proportion (\%) } & \multirow[t]{2}{*}{$95 \% \mathrm{Cl}$} & \multicolumn{2}{|c|}{ Weight (\%) } \\
\hline & & & & Fixed & Random \\
\hline Kuzminin 2019 & 6 & 33.333 & 4.327 to 77.722 & 3.26 & 11.76 \\
\hline Facchinetti 2020 & 153 & 36.601 & 28.970 to 44.762 & 71.63 & 34.99 \\
\hline Imai 2020 & 10 & 30.000 & 6.674 to 65.245 & 5.12 & 15.74 \\
\hline Morita 2020 & 36 & 63.889 & 46.221 to 79.178 & 17.21 & 26.97 \\
\hline Hasegawa 2019 & 5 & 20.000 & 0.505 to 71.642 & 2.79 & 10.54 \\
\hline Total (fixed effects) & 210 & 40.581 & 33.955 to 47.470 & 100.00 & 100.00 \\
\hline Total (random effects) & 210 & 41.532 & 27.140 to 56.704 & 100.00 & 100.00 \\
\hline
\end{tabular}

Test for heterogeneity

\begin{tabular}{|l|l|}
\hline$Q$ & 10.0919 \\
\hline DF & 4 \\
\hline Significance level & $\mathrm{P}=0.0389$ \\
\hline I $^{2}$ (inconsistency) & $60.36 \%$ \\
\hline $95 \% \mathrm{Cl}$ for $^{2}$ & 0.00 to 85.16 \\
\hline & \\
\hline & Publication bias \\
\hline Egger's test & \\
\hline Intercept & 0.05749 \\
\hline $95 \% \mathrm{Cl}$ & -4.5085 to 4.6235 \\
\hline Significance level & $\mathrm{P}=0.9706$ \\
\hline Begg's test & \\
\hline Kendall's Tau & 0.0000 \\
\hline Significance level & $\mathrm{P}=1.0000$ \\
\hline
\end{tabular}

Figure S2 Meta-analysis of disease control for PS $\geq 2$ patients. Q, Cochran's heterogeneity statistic; DF, degrees of freedom. 


\begin{tabular}{|c|c|c|c|c|c|}
\hline \multicolumn{6}{|l|}{ Meta-analysis: proportion } \\
\hline Variable for studies & \multicolumn{5}{|l|}{ First_author } \\
\hline Variable for total number of cases & \multicolumn{5}{|l|}{ total } \\
\hline Variable for number of positive cases & \multicolumn{5}{|l|}{ events_responses_ } \\
\hline \multirow[t]{2}{*}{ Study } & \multirow[t]{2}{*}{ Sample size } & \multirow[t]{2}{*}{ Proportion (\%) } & \multirow[t]{2}{*}{$95 \% \mathrm{Cl}$} & \multicolumn{2}{|c|}{ Weight (\%) } \\
\hline & & & & Fixed & Random \\
\hline Imai, 2020 (40) & 36 & 61.111 & 43.464 to 76.858 & 2.92 & 16.86 \\
\hline Alessi, 2020 (45) & 195 & 43.077 & 36.023 to 50.344 & 15.47 & 21.94 \\
\hline Yamaguchi, 2020 (51) & 29 & 51.724 & 32.531 to 70.551 & 2.37 & 15.81 \\
\hline Cortellini, $2020(30)$ & 756 & 48.148 & 44.533 to 51.777 & 59.75 & 23.14 \\
\hline Friedlander, 2020 (46) & 246 & 71.951 & 65.892 to 77.473 & 19.49 & 22.26 \\
\hline Total (fixed effects) & 1262 & 52.594 & 49.801 to 55.374 & 100.00 & 100.00 \\
\hline Total (random effects) & 1262 & 55.185 & 42.832 to 67.221 & 100.00 & 100.00 \\
\hline
\end{tabular}

Test for heterogeneity

\begin{tabular}{|l|l|}
\hline $\mathrm{Q}$ & 53.7430 \\
\hline $\mathrm{DF}$ & 4 \\
\hline Significance level & $\mathrm{P}<0.0001$ \\
\hline $\mathrm{I}^{2}$ (inconsistency) & $92.56 \%$ \\
\hline $95 \% \mathrm{Cl}_{\text {for }} \mathrm{I}^{2}$ & 85.61 to 96.15 \\
\hline Publication bias & \\
\hline \begin{tabular}{|l|l|}
\hline Egger's test & 1.6587 \\
\hline Intercept & -9.9223 to 13.2398 \\
\hline $95 \% \mathrm{Cl}$ & \\
\hline Significance level & $\mathrm{P}=0.6795$ \\
\hline Begg's test & \\
\hline Kendall's Tau & 0.2000 \\
\hline Significance level & $\mathrm{P}=0.6242$ \\
\hline
\end{tabular} \\
\hline
\end{tabular}

Figure S3 Meta-analysis of objective response for PS = 0-1 patients. Q, Cochran's heterogeneity statistic; DF, degrees of freedom.

\begin{tabular}{|c|c|c|c|c|c|c|}
\hline \multicolumn{7}{|c|}{ Meta-analysis: proportion } \\
\hline \multicolumn{2}{|l|}{ Variable for studies } & \multicolumn{5}{|l|}{ First_author } \\
\hline \multicolumn{2}{|c|}{ Variable for total number of cases } & \multicolumn{5}{|l|}{ total } \\
\hline \multicolumn{2}{|c|}{ Variable for number of positive cases } & \multicolumn{5}{|c|}{ events_disease_control_ } \\
\hline \multirow{2}{*}{\multicolumn{2}{|c|}{ Study }} & \multirow[t]{2}{*}{ Sample size } & \multirow[t]{2}{*}{ Proportion (\%) } & \multirow[t]{2}{*}{$95 \% \mathrm{Cl}$} & \multicolumn{2}{|c|}{ Weight (\%) } \\
\hline & & & & & Fixed & Random \\
\hline \multicolumn{2}{|l|}{ Kuzminin, 2019 (37) } & 74 & 78.378 & 67.276 to 87.107 & 39.68 & 27.50 \\
\hline \multicolumn{2}{|c|}{ Hasegawa, 2019 (36) } & 46 & 63.043 & 47.548 to 76.793 & 24.87 & 25.46 \\
\hline \multicolumn{2}{|l|}{ Imai, 2020 (40) } & 36 & 88.889 & 73.939 to 96.888 & 19.58 & 24.16 \\
\hline \multicolumn{2}{|c|}{ Yamaguchi, 2020 (51) } & 29 & 51.724 & 32.531 to 70.551 & 15.87 & 22.88 \\
\hline \multicolumn{2}{|l|}{ Total (fixed effects) } & 185 & 72.807 & 65.872 to 79.011 & 100.00 & 100.00 \\
\hline \multicolumn{2}{|c|}{ Total (random effects) } & 185 & 71.500 & 56.048 to 84.725 & 100.00 & 100.00 \\
\hline \multicolumn{7}{|c|}{ Test for heterogeneity } \\
\hline \multicolumn{2}{|r|}{14.5952} & & & & & \\
\hline \multicolumn{2}{|r|}{3} & & & & & \\
\hline \multicolumn{2}{|c|}{ Significance level $P=0.0022$} & & & & & \\
\hline \multicolumn{2}{|c|}{$1^{2}$ (inconsistency) $79.45 \%$} & & & & & \\
\hline \multirow{2}{*}{\multicolumn{2}{|c|}{$\begin{array}{l}95 \% \mathrm{Cl}^{\text {for } \mathrm{I}^{2}} \quad 45.28 \text { to } 92.28 \\
\text { Publication bias }\end{array}$}} & & & & & \\
\hline & & & & & & \\
\hline \multicolumn{2}{|l|}{ Egger's test } & & & & & \\
\hline \multicolumn{2}{|l|}{ Intercept } & & & & & \\
\hline & -35.0792 to 26.8932 & & & & & \\
\hline Significance level & $P=0.6271$ & & & & & \\
\hline \multicolumn{2}{|l|}{ Begg's test } & & & & & \\
\hline Kendall's Tau & -0.3333 & & & & & \\
\hline Significance level & $P=0.4969$ & & & & & \\
\hline
\end{tabular}

Figure S4 Meta-analysis of disease control for PS 0-1 patients. Q, Cochran's heterogeneity statistic; DF, degrees of freedom. 